\title{
Sensitive analysis of ground recharge estimation model, for semiarid areas
}

\author{
Salah Eddine Ali Rahmani ${ }^{1}$ (1) $\cdot$ Brahim Chibane ${ }^{1} \cdot$ Abdelkader Boucefiane $^{2}$
}

Received: 24 January 2017 / Accepted: 1 October 2018 / Published online: 10 October 2018

(c) The Author(s) 2018

\begin{abstract}
The rapid demographic evolution wields a big pressure on water resources potentialities; in addition, the climate change effects have influenced the natural renovation rate of water resources around the world. Starting from a previous published model, a sensitive analysis was established after introducing three parameters as watershed topography, stream network density and geology index to illustrate the impact of each of these parameters on the rate of groundwater recharge. This modified model has been improved by in-site experiment (soil chloride mass balance) tested in some selected sites in Sidi Slimane River located in the region of Djelfa at $300 \mathrm{~km}$ from Algiers (Algeria). The results obtained show that the parameters like geology, topography and the amount of rainfall and the drainage density influence the velocity of groundwater recharge. By introducing the chloride concentration in soil, the model becomes most independent and gives good results that can be used in water resources planning in semiarid land.
\end{abstract}

Keywords Water resources potentialities $\cdot$ Climate change $\cdot$ Groundwater recharge $\cdot$ Chloride mass balance $\cdot$ Sidi Slimane River

\section{Introduction}

Water resources management becomes a serious priority for local authorities and the international community. In area where the availability of water depends on the climate conditions, people are happy in wet year and obviously sad in the dry hydrological year. Changes in recharge are controlled by the global warming influences on the dynamic of water cycle around the world (Alcamo et al. 2007). Reduction in rainfall due to climate change in semiarid areas impacts these effects were summarized by the intergovernmental panel on climate changes (IPCC) (Arnel and Lieu 2001). Increasing the temperature of earth will influence the oceanic thermodynamic in large scale; brutal changes will effect the ocean-atmosphere exchange which influences the global atmospheric circulation.

Salah Eddine Ali Rahmani alirahmani101990@gmail.com

1 Geo-Environment Laboratory FSTGAT, USTHB, Bo. 32, El Alia, Bab Ezzouar, 16111 Algiers, Algeria

2 Earth Sciences Department, University of Djilali Bounaama, Khemis Miliana, Algeria
Regions of Africa and the Middle East are the most areas influenced by these changes (Rochdane et al. 2012). Groundwater resources have a high importance in these areas because it secures more than $70 \%$ of water demand of all active sectors like agricultural, industrial and domestic activities (Foster and Chilton 2003).

A strategic plan must be implemented to protect aquifers from a probable depletion and to solve problems of water unavailability in the short and medium range. Many efforts should be made to maintain and optimize the utilization of groundwater resources in semiarid areas (Loucif Seiad 2003).

The good quantification of the rate of groundwater recharge is based on two principal ideas:

- The availability of sufficient data with good quality.

- The relationship between the used technique and the physical reality of the watershed, for example, methods used to quantify recharge in shallow groundwater aquifers cannot be used for karstic aquifers where the velocity of groundwater flow is more important than the other hydrogeological systems. 
In this paper, we present a previous published model (Ali Rahmani et al. 2016) to quantify groundwater recharge by introducing some parameters to make the model more useful and dynamic for all semiarid sites. It can be used in geographic information systems (GIS) to establish map of spatial variation of groundwater recharge and map of sensitive areas to different sources of pollution.

\section{Groundwater recharge process}

The infiltration rate of rainfall depends on the soils' texture, the geologic setting of the recharge areas, the topographical configuration of the watershed and essentially the hydroclimatic conditions (precipitation, temperature, wind speed and direction, the air moisture).

In summer, the high amount of rainfall results from aggressive storms that cannot reach the aquifer, but it returns the atmosphere by the bias of the evapotranspiration; in this case, the evapotranspiration intensity is greater than the recharge process. The recharge process consists of three forms: localized recharge, direct recharge and indirect recharge (inter-flow) (Fig. 1).

\section{The new model and aquifers' artificial recharge and recovery}

Artificial recharge of aquifers is a needed strategy for water resources reinforcement in semiarid regions. The new model will be of interest to select the favorable area for aquifer recharge based on five input layers (temperature, rainfall, slope, stream network density and the geology of the basin).

\section{Materials and methods}

\section{Study area}

The Oued Djelfa-Melah watershed (Fig. 2) was located at $290 \mathrm{~km}$ south to the capital of Algeria (Algiers). It was under Mediterranean climate (semiarid type), with a cold and rainy winter and a hot, dry summer, with annual rainfall of around $336 \mathrm{~mm}$. The inter-annual average temperature is $14.6{ }^{\circ} \mathrm{C}$. The calculation of the water balance by the method of Thornthwaite revealed that evapotranspiration gives a value of $804.66 \mathrm{~mm}$ and an ETR of $278.12 \mathrm{~mm}$ (Chibane 2010) (Fig. 3).

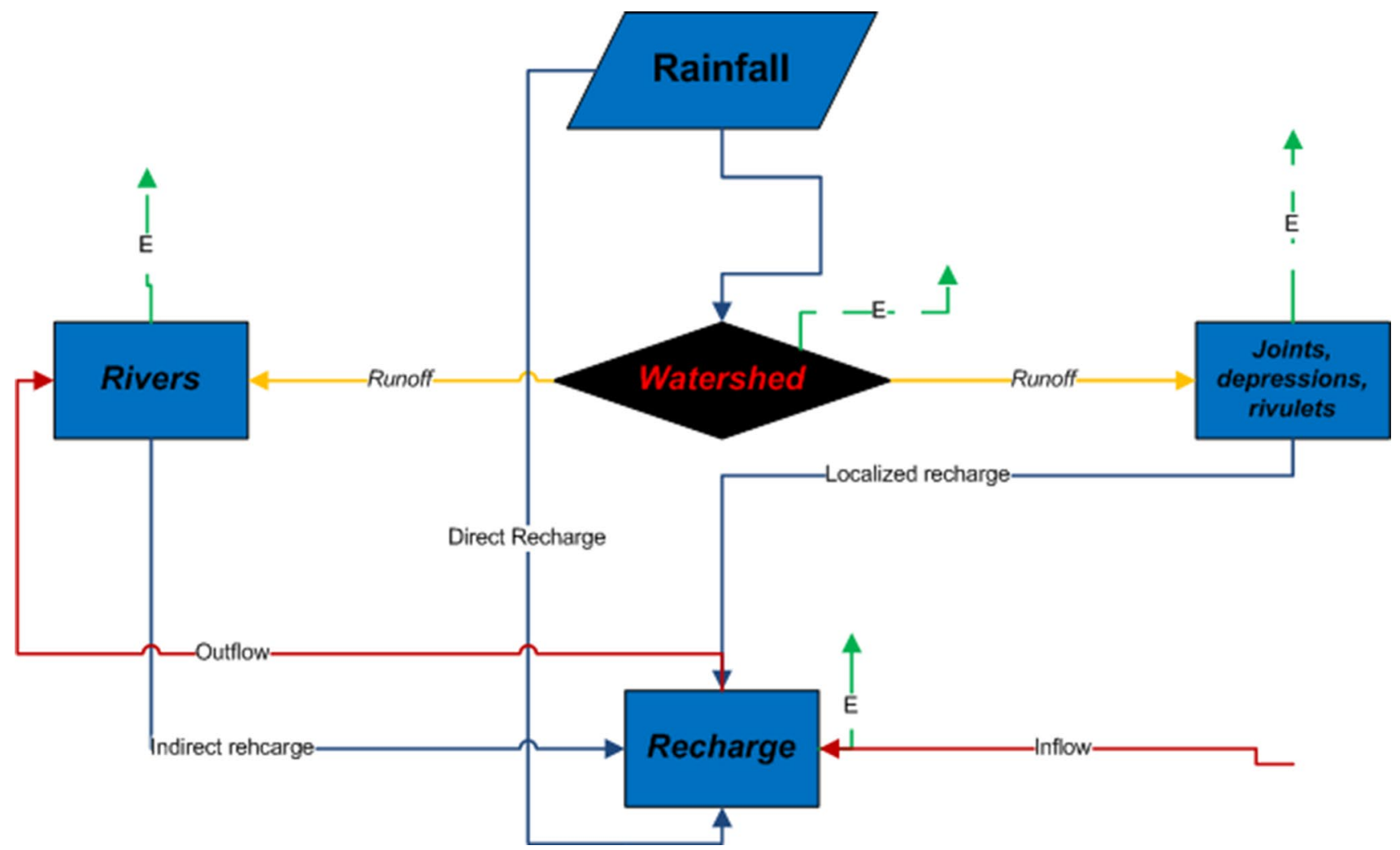

Fig. 1 Groundwater recharge mechanism (De Vries and Simmers 2002) modified 


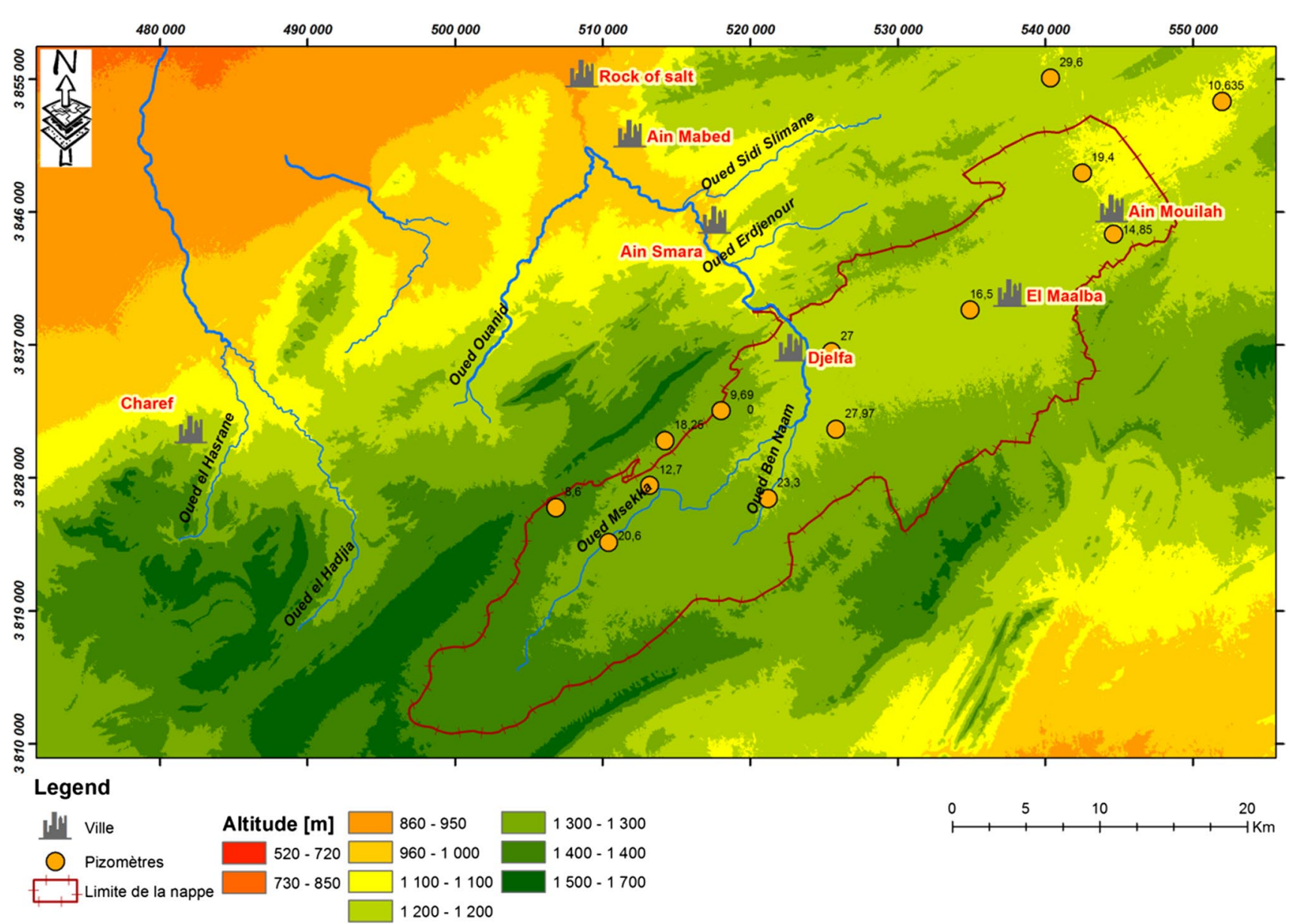

Fig. 2 Study area (watershed of Djelfa-Melah River)

The region of Djelfa is formed by different geological deposits (Fig. 4); the major deposits are described in chronological order as the following (Chibane and AliRahmani 2015).

The Triassic appears in the form of diapirs; the outcrop of this type of deposits is known in the Djelfa region by the "Salt Rock," located at $20 \mathrm{~km}$ north of Djelfa.

The Neocomian is impermeable bedrock; it forms the reliefs of El-Kef-Haouas and Djebel Aissa, with a thickness that reaches $800 \mathrm{~m}$. It is mainly formed by series of clay sandstone.

The Barremian formation is essentially consisting of alternating sandstones and sandy clays intensely cracked, the Barremian forms the major aquifer capacity, and its thickness ranges from 1500 to $2000 \mathrm{~m}$.

The Aptian forms a waterproof substratum (Aquitard) of the Albian and shows a continuous narrow strip that appears in the northern and southern flanks, discontinuous, sometimes hidden by quaternary deposits. The thickness of this formation is about $200 \mathrm{~m}$ to the west and $100 \mathrm{~m}$ to the east.
The Albian Struck flushes all around the syncline, and it consists of massive sandstone fine. There are also of gray clays. The lower Albian forms a productive aquifer and its thickness is about $400 \mathrm{~m}$. The upper Albian is about $200 \mathrm{~m}$ thick, consisting of limestone and marl alternating; this part represents a waterproof part.

The Turonian formation is composed of fractured limestone with alternations of marls in its uppermost part. Its thickness is around $450 \mathrm{~m}$, and it forms a karstic aquifer.

The Mio-Plio-Quaternary is mainly sandy, silty and conglomeratic and is surmounted by a calcareous crust; due to its low permeability, the Mio-Plio Quaternary is operated by small wells; its thickness is variable $(250-300 \mathrm{~m})$.

\section{Model context}

Based on a recent model published by Ali Rahmani et al. (2016), a sensitive study of the physical context of this hydrological-based model was established by introducing two factors: topography of the basin and stream network density to 


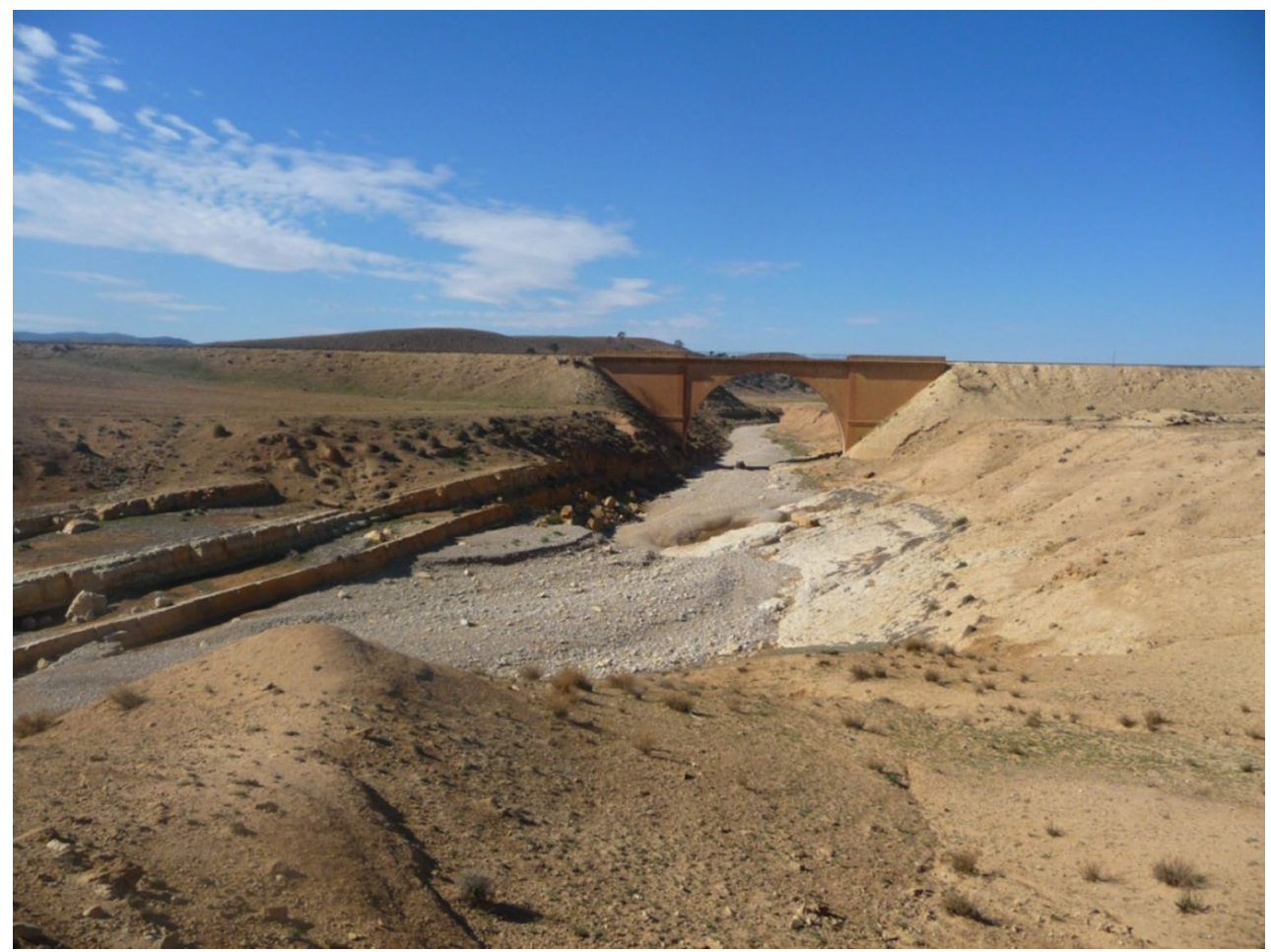

Fig. 3 Sidi Slimane River (March 2016)

extend the model efficiency; the calibration process was done by using soil chloride mass balance (Allison 1988).

The general form of the equation of this model is given by Eq. (1), and the detailed description is given in Table 1:

$\mathrm{Gw}=\alpha \times[P-(P-1) \times \beta] \times \gamma$,

where $\alpha$ and $\beta$ are the temperature-dependent coefficients and $\gamma$ is the adjustment coefficient.

\section{Modified groundwater recharge (Gwm)}

Equation (1) is modified by introducing another three parameters to make the model more representative of the hydrological process; these three parameters are topography coefficient, geology index and stream network density. The efficiency of the model reduces the over-estimation of groundwater recharge and makes our water resources planning strategy more reasonable.

By the combination of these factors, the new modified model can be used to draw a potential recharge map and area with high and low vulnerability of aquifers to pollution sources.

The general form of the modified model equation is given by Eq. (2):

$\mathrm{Gwm}=\mathrm{Gw} \times \mathrm{Gf} \times \mathrm{Tf}+\mathrm{Ddf}$, where $\mathrm{Gw}$ is the groundwater recharge estimated by Ali Rahmani et al. (2016) model, Gf is the geological factor that describes the permeability of soil, Tf is the topography factor that describes the basin inclination, and Ddf is the drainage density expressed as a part of average runoff.

Based on theoretical data about characteristics of geological deposits, topographical settings and drainage density, a weighed rate was given for each of these parameters as the following:

\section{Geological factor (Gf)}

Groundwater recharge rate depends not only on the amount of rainfall, but also on the geological settings of the watershed which are important in the recharge process. Permeable deposits permit rapid infiltration against impermeable (Castany 1982).

Here, the geological factor was introduced in the modified model as a fraction of the total effective precipitation (Banton and Bangoy 1997; Duda et al. 2011). These coefficients are given in Table 2.

\section{Topography of the watershed (Tf)}

Topography is an essential parameter in the hydrological process (runoff, sediments transport and groundwater recharge). 


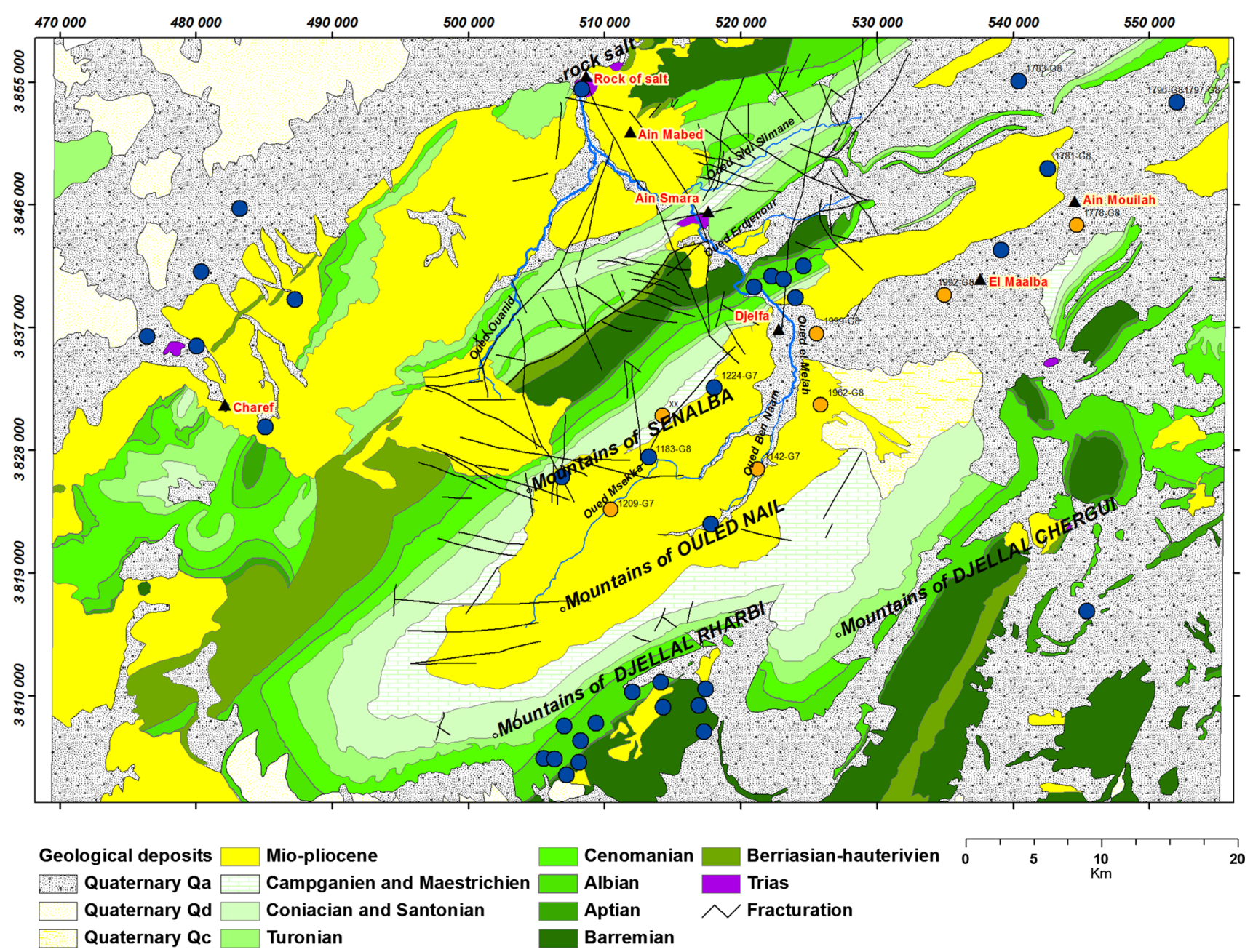

Fig. 4 Geological map of the study area

Table 1 Parameters of the model

\begin{tabular}{llll}
\hline Abbreviation & Description & Unit & Equation \\
\hline $\mathrm{Gw}$ & $\begin{array}{l}\text { Average annual rate of groundwater } \\
\text { recharge }\end{array}$ & $\mathrm{mm}$ & $\mathrm{Gw}=\alpha \times[P-(P-1) \times \beta] \times \gamma$ \\
$P$ & Average annual rainfall & $\mathrm{mm}$ & - \\
$\alpha$ & Temperature coefficient & - & $\alpha=\frac{T^{2}-1}{T^{2}-12 T}$ \\
$\beta$ & Temperature coefficient & - & $\beta=\frac{\sqrt{T^{2}-1}}{T}$ \\
$\gamma$ & Adjustment coefficient & - & $\gamma=T^{0.21}$ \\
\hline
\end{tabular}

Table 2 Geological settings factor value for permeable, semipermeable and impermeable layers

\begin{tabular}{lll}
\hline Geology of basin & Gf & Description \\
\hline Impermeable deposits & 0.1 (less than 1\%) & $\begin{array}{l}\text { Very low permeability does not mean there is low recharge, but the } \\
\text { velocity of recharge is very low; recharge in these deposits can be } \\
\text { done by a phenomena called delayed recharge (silt, gypsum, clay } \\
\text { rocks) }\end{array}$ \\
$\begin{array}{ll}\text { Medium permeability } \\
\text { High permeability }\end{array}$ & $\begin{array}{l}\text { Medium permeability (sand, marl, sandy loam, etc.) } \\
\text { High permeability capacity (gravels, alluvium) }\end{array}$ \\
\hline
\end{tabular}

High permeability

0.9 (less than 6\%) 
Table 3 Topographical factor (Tf) values

\begin{tabular}{lcc}
\hline Topography (slope) & Tf & Description \\
\hline High & 0 & $\begin{array}{l}\text { Zone with high slope (more than } 20^{\circ} \text { ) does not promote infiltration, because the inclination of the layer gives kinetic } \\
\text { energy to the precipitations and decreases the time of concentration of water which arises its velocity; in this case, } \\
\text { the rainfall will transform to surface runoff } \\
\text { Medium }\end{array}$ \\
Low & $\begin{array}{l}\text { Medium slope (less than } 15^{\circ} \text { ) participates with medium range in the groundwater recharge process; it lets infiltration } \\
\text { of only } 50 \% \text { of the possible infiltration volume } \\
\text { Low slope helps in groundwater recharge by reducing the velocity of surface runoff and lets the direct infiltration of } \\
\text { rainfall by increasing the time of concentration of precipitation in a specific area (gravels, alluvium) }\end{array}$ \\
\hline
\end{tabular}

To give the model more aptitude to adapt with physical context of the watershed, a topographical weight factor was assigned to the new modified model. The selection of slope coefficient is uniformized according to the digital elevation model.

The description of these weights is given in Table 3 .

\section{Drainage density}

The stream network along the basin describes the stream flow and surface runoff in function of the length of each stream. The influence of drainage density factor was introduced in the model as a fraction of average annual runoff that supplies the aquifer by the bias of the inter-flow phenomena (McClain et al. 2014).

\section{Limit of application of the model}

To apply the model, the following conditions must be verified to get good results:

- The average annual temperature must be great than or equal to $12.8^{\circ} \mathrm{C}$.

- The hydrological system must be closed, and exchange between watersheds must be assumed negligible.

\section{Results and discussion}

The main results are discussed in this section of the paper, starting by calculating the average recharge for normal conditions in relation with basin topography, geological morphology and drainage density factors. The results obtained were compared with in-site experiments.

The novelty of this modified model in this paper is the three parameters introduced in the main model developed by Ali Rahmani et al. (2016). Introduced parameters take in interest the physical form of the watershed, the geology and the stream networks in the entire basin (Table 4).

The model becomes more dynamic and elastic, and it can give a very good result to quantify groundwater recharge rate in semiarid area.

Topography has great effects on groundwater recharge process. The slope controls the velocity of the runoff and the groundwater hydraulic which means every time the slope is high; the precipitations will transform to direct runoff. Topography factor was devised to three classes: The first class has 0 weight for slope more than $20^{\circ}$; in this case, the topography favors the runoff and the groundwater recharge may approach zero.

The second class has 0.5 weight, for less than $15^{\circ}$; in this situation, a small part of precipitation will infiltrate and the other part will transform to direct runoff.

The last class has 1 weight, when the slope is less than $8^{\circ}$; velocity of runoff is low, and precipitation becomes more concentrated in the land to promote an effective infiltration of rainwater.

Table 4 Drainage density class

\begin{tabular}{lll}
\hline Drainage density (Dd) & Dd & Description \\
\hline Low & 0 & $\begin{array}{c}\text { Low drainage density means that there is a little aquifer-river exchange, and the aquifer supply was done } \\
\text { only by effective } \\
\text { rainfall } \\
\text { Medium }\end{array}$ \\
High & Dd10\% & $\begin{array}{l}\text { Medium density participates with medium range in the groundwater recharge process; it lets infiltration } \\
\text { High Dd helps in groundwater recharge by increasing the infiltration via streams and rivers (inter-flow } \\
\text { phenomena) }\end{array}$ \\
\hline
\end{tabular}

With Dd1\% $=\frac{(0.01 \times P)^{2.4}}{100}$ and Dd10\% $=\frac{(0.01 \times P)^{2.4}}{10}, P$ is the average annual runoff 


\section{Chloride mass balance}

\section{Theoretical background}

Several researchers have used chloride profiles to calculate water fluxes in the unsaturated zone (Allison and Hughes 1983; Bromley et al. 1997; Scanlon 1991; Scanlon and Goldsmith 1997).

Chloride is a useful geochemical tracer of water movement in the unsaturated zone because it is chemically conservative and generally is not a favorite element to vegetation and plants. The one-dimensional chloride transport in the unsaturated zone under steady-state conditions is described by the following equation (Scanlon and Goldsmith 1997):

$q_{\mathrm{Cl}}=C_{\mathrm{Cl}} q-D_{\mathrm{h}} \frac{c_{\mathrm{Cl}}}{z} q=\frac{q_{\mathrm{Cl}}}{C_{\mathrm{Cl}}}$, where $q_{\mathrm{Cl}}$ is the chloride flux at the land surface, $C_{\mathrm{Cl}}$ is the chloride concentration in soil water, $q$ is the water flux, and $D_{\mathrm{h}}$ is the hydrodynamic dispersion coefficient.

The term $D_{\mathrm{h}} \frac{{ }_{\mathrm{Cl}}}{z}$ is assumed negligible for some semiarid areas (Bromley et al. 1997).

This method helps us to calculate recharge by taking into account the chloride balance between the atmospheric dray and wet deposit and the chloride concentration in soils. This tracer-based method is useful in semiarid and arid areas.

Thirteen soil profiles were realized in the Sidi Slimane River in the region of Djelfa, we have analyzed the chloride concentration in soil at different depths, the standard depth used for all layers is equal to $100 \mathrm{~cm}$, and the details about the method are reported by Ali Rahmani et al. (2017).

Figure 5 shows the infiltration rate via the unsaturated layers along the two banks of the river.

Groundwater recharge variation is shown in Fig. 5, it was calculated using the chloride mass balance, and the total atmospheric flux of chloride was measured to be $15 \mathrm{mg} / \mathrm{l}$
Fig. 5 Chloride concentration and groundwater recharge calculated for the 13 profiles (Ali Rahmani et al. 2017)
Fig. 6 Saline bedrock shown in the 2D contour plot for the profiles P9-P12
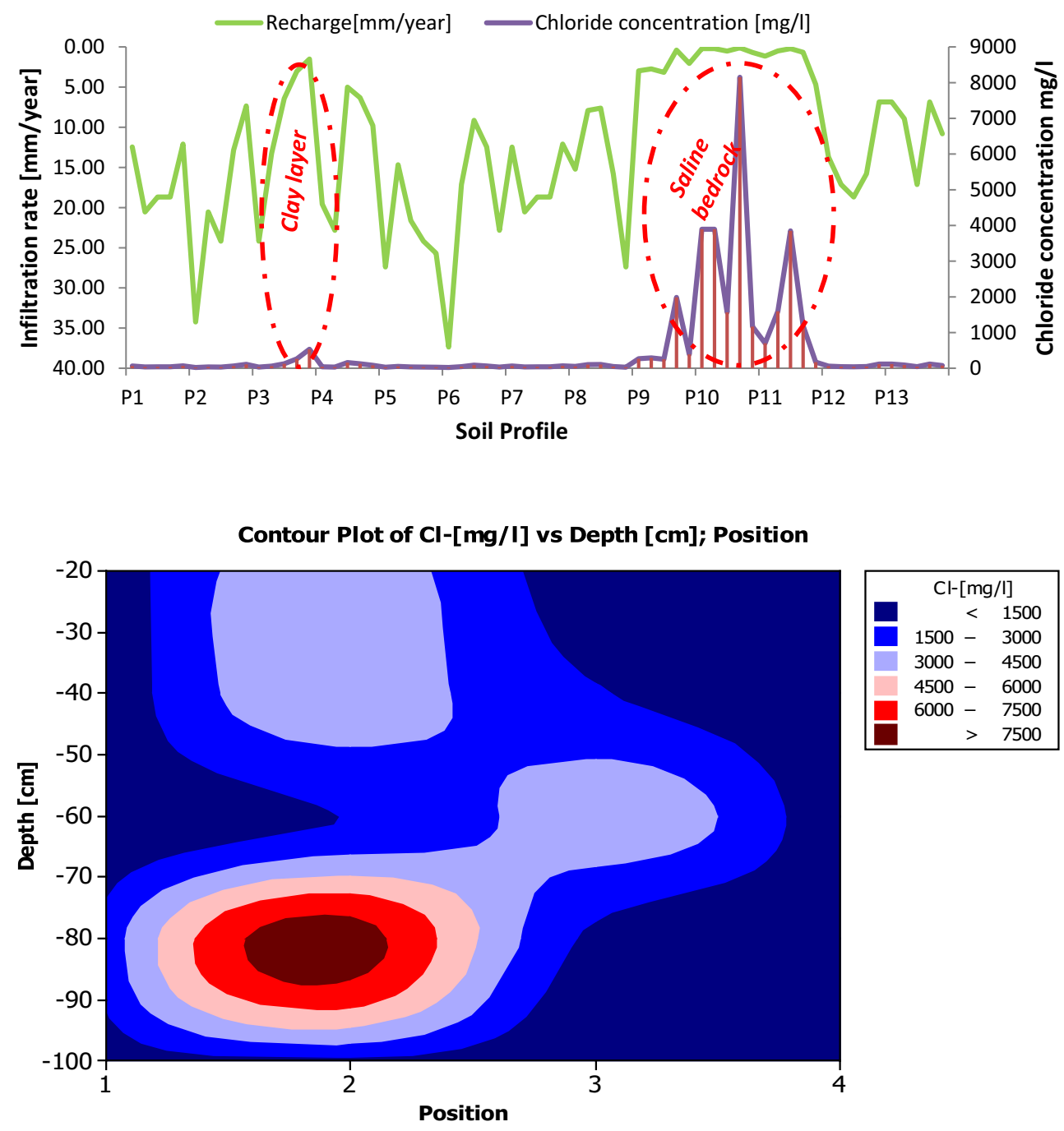
(Moulla and Guendouz 1996) for a mean average annual rainfall of $320 \mathrm{~mm}$ (Fig. 6).

The recharge rate calculated along the river border ranges from 0.10 to $37.35 \mathrm{~mm} /$ year with an average of $12.39 \mathrm{~mm} /$ year.

The chloride concentration in soil profiles was varied between 21.42 and $8150.14 \mathrm{mg} / \mathrm{l}$ with a mean of $509.87 \mathrm{mg} / \mathrm{l}$ with a coefficient of variation of $253 \%$ which explains the heterogynous of soil profiles in the horizontal and vertical axes along the river. $T$ test was established to be the value of average estimated groundwater recharge by the soil profile methods; the $T$ test criteria are defined if the average of recharge is less than $15 \mathrm{~mm} / \mathrm{year}$, and the results of this test are shown in Fig. 7.

This test lets us to calculate the corrected average annual recharge with a confident bound of $90 \%$; the value lies between 10.489 and $14.286 \mathrm{~mm}$ /year.

The model of Ali Rahmani et al. gives for the same precipitation $13 \mathrm{~mm} /$ year which lets us to conclude that the model efficiency is good. In the same way, the idea presented in this paper is the dependence of the groundwater recharge process on the climatic conditions, on the geological settings and on the topographical factors and drainage density of the basin.

However, the experimental study lets us to confirm the result given by the new modified model; the introduced parameters let the water resources manager to establish a map of potential recharge.

Figure 8 shows the map recharge obtained from this model, in the region of study. The map shown in Fig. 8 shows the spatial variation of groundwater recharge. It ranges from 2.7 to $24 \mathrm{~mm}$. The mean is $12 \mathrm{~mm} /$ year which approaches the values founded in Sidi Slimane River (12.38 mm/year).

\section{Recommendations}

This new experiment lets us to conclude that ground recharge process is not dependent only on two entries (precipitations and temperature); by introducing another three parameters, Ali Rahmani et al. model becomes more dynamic to be used for the complicated semiarid areas where recharge is limited by topographical, geological and drainage density factors. However, the chloride mass balance experiment gives us a good understanding of the recharge process across the unsaturated zone, where the climate change and soil layers are the major factors that determine which quantity of water will reach the saturated zone.

The advantages given by this model are related to five principal parameters (precipitation, temperature, geology, topography and drainage density of the basin) which

\section{1-Sample $t$ Test for the Mean of GWRcmb Summary Report}
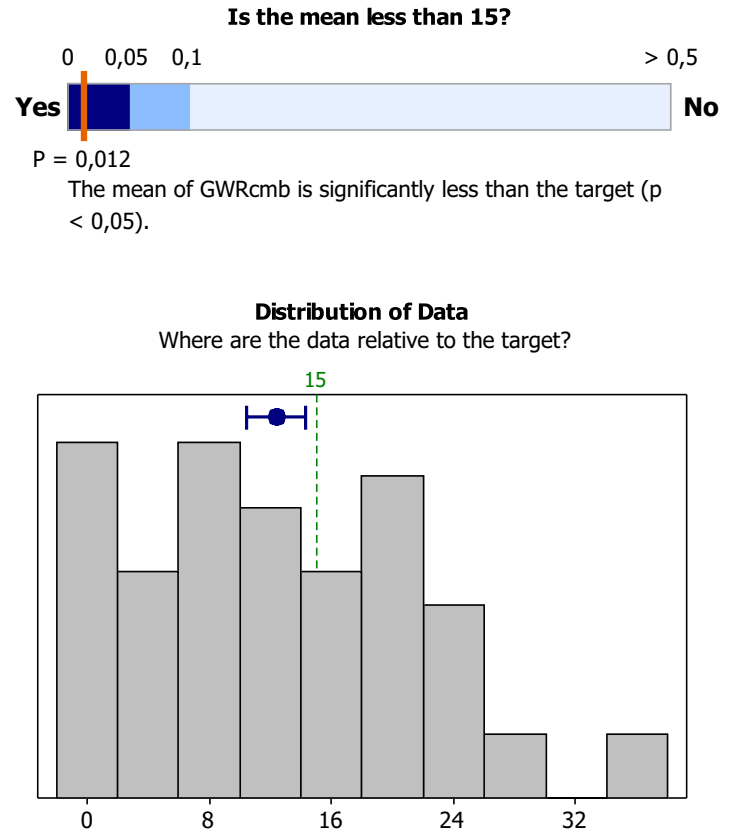

\section{Statistics}

\begin{tabular}{lr}
\hline Sample size & 65 \\
Mean & 12,388 \\
$90 \%$ CI & $(10,489 ; 14,286)$ \\
Standard deviation & 9,1727 \\
Target & 15
\end{tabular}

\section{Comments}

-- Test: You can conclude that the mean is less than 15 at the 0,05 level of significance.

-- CI: Quantifies the uncertainty associated with estimating the mean from sample data. You can be $90 \%$ confident that the true mean is between 10,489 and 14,286.

-- Distribution of Data: Compare the location of the data to

the target. Look for unusual data before interpreting the

test results.

Fig. 7 Sample $t$ test for the mean of GWRcmb 


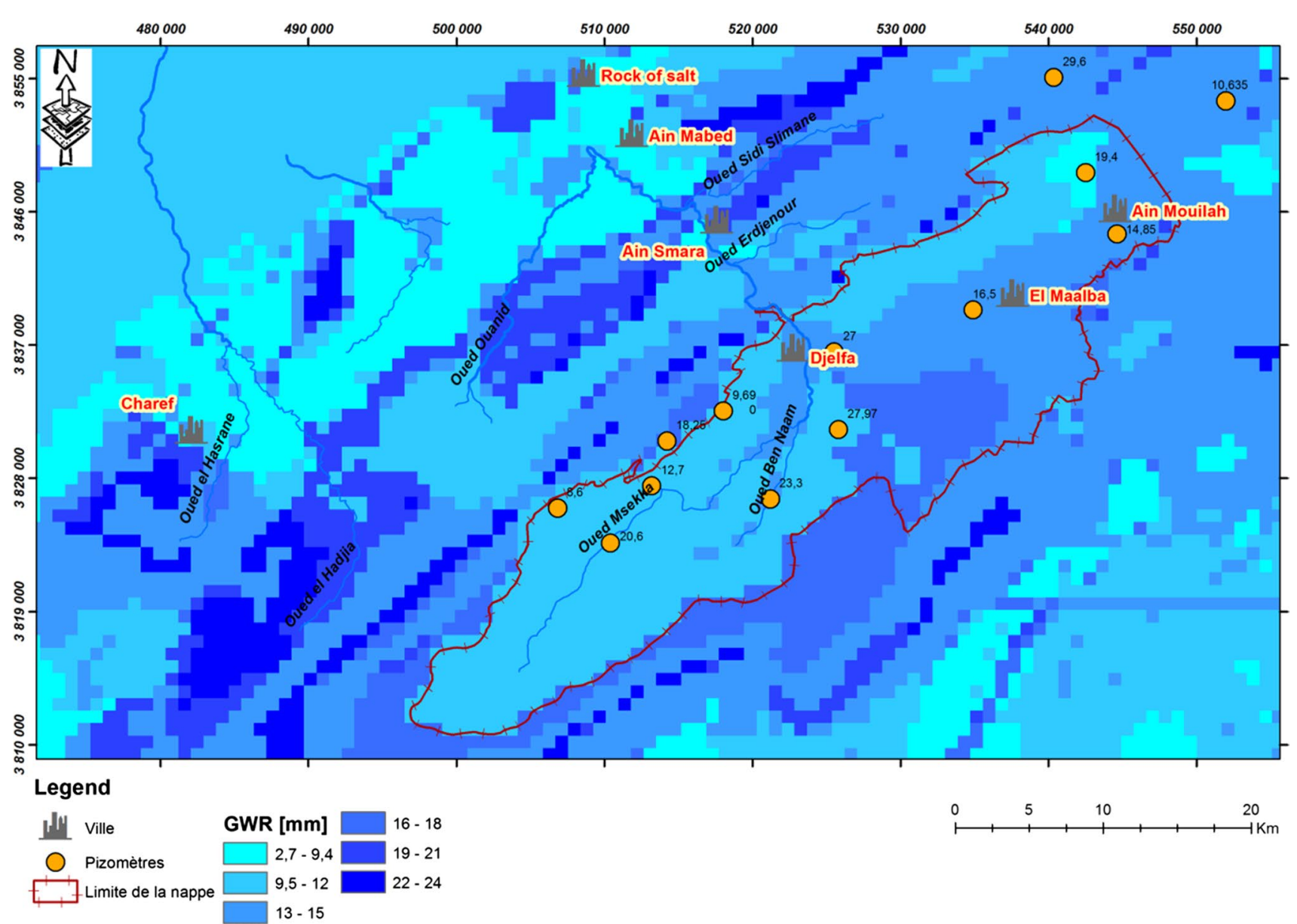

Fig. 8 Groundwater recharge map

make the estimation of groundwater recharge rate with low uncertainty.

\section{Conclusion}

Recharge estimation is effectuated by introducing a modified previous model. This model is the combination of five input parameters: rainfall, temperature, geology, topography and drainage density. The calibration of model was done by using a chloride mass balance designated to the unsaturated zone. The in-site experiment shows that the groundwater recharge rate varies from 0.10 to $37.35 \mathrm{~mm} /$ year with an average of $12.39 \mathrm{~mm} /$ year. The model gives an average of $13 \mathrm{~mm} /$ year. This approach will help water resources manager in semiarid areas to evaluate the annual rate of aquifer recharge to control the abstraction of water and manage water more rationally. The importance of this model is to establish a map of recharge that helps us in the delimitation of areas with high water potentiality. Our actual research are focused to perform this model to use it in simulation of the aquifer response in function of two variables: the rapid demographic growth and climate change scenario.

Open Access This article is distributed under the terms of the Creative Commons Attribution 4.0 International License (http://creativeco mmons.org/licenses/by/4.0/), which permits unrestricted use, distribution, and reproduction in any medium, provided you give appropriate credit to the original author(s) and the source, provide a link to the Creative Commons license, and indicate if changes were made.

\section{References}

Alcamo J, Florke M, Marker M (2007) Future long-term changes in global water resources driven by socio-economic and climatic changes. Hydrol Sci J 52(2):247-275. https://doi.org/10.1623/ hysj.52.2.247

Ali Rahmani SE, Chibane B, Boucefiène A (2016) Groundwater recharge estimation in semi-arid zone: a study case from the region of Djelfa (Algeria). Appl Water Sci. https://doi. org/10.1007/s13201-016-0399-y

Ali Rahmani SE, Chibane B, Hallouz F, Boutelba A, Aiachi N (2017) New modified green-AMPT models to calculate water 
flux via unsaturated layers, case of Sidi Slimane river (Algeria). LARHYSS J 32:1112-3680

Allison GB (1988) A review of some of the physical, chemical and isotopic techniques available for estimation ground-water recharge. In: Simmers I (ed) Estimation of natural groundwater recharge. Reidel Publishing Co., Dordrecht, pp 49-72

Allison GB, Hughes MW (1983) The use of natural tracers as indicators of soil-water movement in a temperate semi-arid region. $\mathrm{J}$ Hydrol 60:157-173

Arnel N, Lieu C (2001) Hydrology and water resources. In: Climate change, 2001, impact, adaptation, and vulnerability. Intergovernmental panel on climate change. Cambridge University Press, Cambridge

Banton O, Bangoy LM (1997) Hydrogéologie-multiscience environnementale des eaux souterraines. Aupelf Uref. Presses De l'Université Du Québec, p 460

Bromley J, Edmunds WM, Fellman E, Brouwer J, Gaze SR, Sudlow J, Taupin JD (1997) Estimation of rainfall inputs and direct recharge to the deep unsaturated zone of southern Niger using the chloride profile method. J Hydrol 188-189:139-154

Castany G (1982) Principes et méthodes de l'hydrogéologie. Dunod, Paris, France

Chibane B (2010) Hydrogeological and hydrogeochemical study in semi-arid area: case study of the Djelfa region. $\mathrm{PhD}$ thesis in hydrogeology, FSTGAT, USTHB, Algeria

Chibane B, Ali-Rahmani SE (2015) Hydrological based model to estimate groundwater recharge, real evapotranspiration and runoff in semi-arid area. LARHYSS J 23(23):1112-3680

De Vries JJ, Simmers I (2002) Groundwater recharge: an overview of processes and challenges. Hydrol J 10:5-17. https://doi. org/10.1007/s10040-001-0171-7

Duda R, Witczak S, Zurek A (2011) Map of ground water vulnerability to pollution in Poland, a scale of 1:500,000-methodology and text explanations (in Polish with English summary). Ministerstwo Erodowiska, Warszawa

Foster SSD, Chilton PJ (2003) Groundwater: the processes and global significance of aquifer degradation. Philos Trans R Soc Lond B 358:1957-1972

Loucif Seiad N (2003) Les ressources en eau et leurs utilisations dans le secteur Agricole en Algérie. Revue H.T.E. No. 125 mars 2003

McClain ME, Subalusky AL, Anderson EP, Dessu SB, Melesse AM, Ndomba PM, Mtamba JOD, Tamatamah RA, Mligo C (2014) Comparing flow regime, channel hydraulics and biological communities to infer flow-ecology relationships in the Mara River of Kenya and Tanzania. Hydrol Sci J 59(3-4):801-819

Moulla AS, Guendouz A (1996) A survey of rainwater chemical and isotopic composition in North Algeria. Séminaire International sur l'Application des Techniques Isotopiques dans le Domaine des Ressources en Eau et en Sol. Mahdia, Tunisia, 14-18 June 1996

Rochdane S, Reichert B, Messouli M, Babqiqi A, Khebiza MY (2012) Climate change impacts on water supply and demand in Rheraya Watershed (Morocco), with potential adaptation strategies. Water 4:28-44. https://doi.org/10.3390/w4010028

Scanlon BR (1991) Evaluation of moisture flux from chloride data in desert soils. J Hydrol 128:137-156

Scanlon BR, Goldsmith RS (1997) Field study of spatial variability in unsaturated flow beneath and adjacent to playas. Water Resour Res 33:2239-2252

Publisher's Note Springer Nature remains neutral with regard to jurisdictional claims in published maps and institutional affiliations. 